\title{
Bilişsel Davranış̧̧ı Yaklaşım Temelli Bir Psikolojik Danışma Programının Ergenlerin Sosyal Fobi ve Mizah Düzeylerine Etkisi*
}

\section{The Effect of a Cognitive-Behavioural Psychological Theory Based Psychological Counselling Program on Adolescents' Social Phobia and Humor Level}

\author{
Umut KERMEN**, Seval ERDEN***
}

\begin{abstract}
Öz: Bu çalışmanın amacı bilişsel davranışçı yaklaşım temelli bir psikolojik danışma programının, ergenlerin sosyal fobi ve mizah düzeylerine etkisini incelemektir. Araştırmanın çalışma grubunu Kocaeli ilinde bir lisede öğrenim görmekte olan 13 deney, 13 kontrol grubunda olmak üzere 26 öğrenci oluşturmaktadır. 10 haftalık grupla psikolojik danışma uygulamasının ardından, programın etkililiği MannWhitney U ve Wilcoxon Testi ile analiz edilmiştir. Elde edilen bulgulara göre, uygulanan program sonunda deney grubundaki katılımcıların sosyal fobi puanları düşerken, mizah puanları yükselmiştir.
\end{abstract}

Anahtar Kelimeler: Bilişsel-davranışçı yaklaşım, psikolojik danışma, sosyal fobi, mizah, ergenler

\begin{abstract}
Aim of this study was to examine the effect of a cognitive-behavioural theory based psychological counselling program on adolescents' social phobia and humor level. The study group consisted of 26 students, 13 of whom were in the control group and 13 of them were studying in a high school in Kocaeli. After 10 weeks of group counselling, the effectiveness of the program was analysed by using Mann-Whitney U and Wilcoxon Test. According to the findings, while the social phobia scores of the participants in the experimental group decreased, humor scores increased at the end of the program.
\end{abstract}

Keywords: Cognitive-behavioural approach, psychological counselling, social phobia, humor, adolescents

\section{Giriş}

Ergenlik döneminde insanlar, sosyal rollerini öğrenmektedirler. Öğrenilen sosyal roller arasıda ise nasıl bir öğrenci, arkadaş, vatandaş ya da eş olabileceği bulunmaktadır. Roller ise toplumdaki aile, arkadaşlar gibi yapılarla iletişim ve etkileşim içinde öğrenilmektedir. Sosyal fobinin getirdiği, sosyal ortamlarda utangaçlık, içe dönme, kaçınma rollerin öğrenilmesine engel olabilir. Sosyal fobi ise "kişinin başkalarınca değerlendirileceği durumlarda sürekli korku hissetme; diğer insanlar tarafında aşağılanacağını düşünme, bu durumdan dolayı utanç duyacağı ya da diğer insanları gözünde gülünç duruma düşeceğinden korkma" olarak tanımlanmıştır (Mcnail ve Randall, 2014). Sosyal fobiye sahip kişiler sosyal ortamlarda, performans göstermesi gereken anlarda olumsuz değerlendirilme endişesi ve küçük düşme kaygısı ile korku yaşarlar. Korku sosyal fobiye sahip kişilerin, aşırı düzeyde kendilerinin farkında olmasına ve kendilerini eleştirme eğilimlerine sebep olmaktadır. Bu duygular ile vücut kızarma, çarpıntı, terleme ve titreme gibi fizyolojik tepkiler vermektedir (Dilbaz, 1997). Amerika Psikiyatri Birliği (2013) DSM-V içinde sosyal fobiyi bir hastalık olarak değerlendirmiş ve tanı için bir takım kriterler öne sürmüştür. Bunlar kişinin, başkalarınca değerlendirilebilecek olduğu sosyal durumda kendini belli eden

\footnotetext{
* Hazırlanan ve uygulanan program, Marmara Üniversitesi Rehberlik ve Psikolojik Danışmanlık doktora programı Bilişsel-Davranışçı Kuram ve Uygulamaları dersinde, ders öğretim üyesi süpervizyonunda hazırlanmış ve uygulanmıştır.

** Doktora Öğrencisi, Marmara Üniversitesi, Eğitim Fakültesi, İstanbul-Türkiye, ORCID: 0000-0002-8618-7560, eposta: umutkermen@gmail.com

*** Doç. Dr., Marmara Üniversitesi, Eğitim Fakültesi, İstanbul-Türkiye, ORCID: : 0000-0002-4512-1274 ,e-posta: seval.erden@marmara.edu.tr
} 
korku ya da kaygı duyması; kişinin, kendini olumsuz olarak gösterebilecek şekilde davranmaktan veya kaygısını belli eden belirtiler göstermekten korkmas1; bu sosyal durumların her zaman korku veya kaygı yaratması, sosyal durumlardan kaçınılması, eğer kaçınamıyorsa büyük bir korku ya da kaygı ile katlanılması; duyulan korku ve kaygının toplumsal kriterlere göre orantısız olması; yaşanılan duyguların veya kaçınmanın süreklilik göstermesi ve altı ay ya da daha uzun süreden beri var olması şeklinde sıralanmıştır. Ergenlerde sosyal fobi incelendiğinde ise, sosyal fobinin çocuk ve ergenler için, yaygınlık oranı en yüksek psikolojik bozukluk olduğu belirtilmektedir. Burstein, He, Kattan, Albano, Avenevoli ve Merikangans (2011) 13-18 yaşları arasındaki kız ergenlerin \%9.2'sinin, erkek ergenlerin ise \% 7.9'unun sosyal fobi yaşadığını belirtmektedir. Ayrıca sosyal fobi oluşma yaşı da 9.2 yaş olarak saptanırken; ortalama 6 yıl sürdüğü de bulgular arasındadır. Bu kadar erken başlangıcı olan ve uzun süre kişi ile birlikte olan rahatsızlıkta, sosyal fobiye sahip olanların sadece \%8,6's1 tedaviye başvurmaktadır. Düşük tedavi başvuru oranı, sosyal fobinin, kişilerde tedavi edilmeden kaldığııı göstermektedir.

Sosyal fobiye bakış açısı getiren yaklaşımlardan biri bilişsel yaklaşımdır. Bilişsel yaklaşımlara göre sosyal fobisi olanlar, sosyal olayları tehdit edici görürler. Sosyal olaylar bağlamında kendileriyle ya da davranışlarıyla ilgili çarpıtmalar geliştirler. Bu çarpıtmalar, "kaygı duyduğumu anlamalarına izin vermemeliyim" gibi yapacağı davranış için aşırı beklentiler; değerlendirilmeyle ilgili "düşüncem yanlışsa kötü duruma düşerim" gibi şartlı sayıltılar; kişinin kendiyle ilgili "yetersiz, sıkıcı, sevilmeyen bir insanım" gibi temel inançlardan kaynaklanmaktadır (Stein ve Hollender, 2002). Sosyal fobisi olanların çarpıtmaları, diğer insanların değerlendirmelerinden kaynaklanmaz. Sosyal fobisi olanların olumsuz inançları, başka insanların cevaplarını gözlemekten değil, nasıl göründüklerine ilişkin başkalarına verdikleri izlenimlerden kaynaklanmaktadır. Bu durumda kişiler, ne olduğu ile ilgilenmez, korktukları durumun sonucunda oluşan duygularına dikkat etmektedirler. Sosyal fobi ile utanma duygusu ise birbirinden farklıdır. Utangaç insanlar, sosyal ilişkilere girebilirken, diğer insanları gözlerler ve onların yorumlarını dikkate alırlar; kabul ediklerini gördüklerinde kaygıları sonlanır. Sosyal fobiye sahip olanlar ise, bu değerlendirmeyi yapmazlar. Diğer insanların kendilerini nasıl değerlendiğini düşünmezler; olumsuz değerlendirilme riskini arttıracağı için, tehdit edici olarak algılanır (Tükel, 2009).

Sosyal fobiye sahip kişilerin düşünce yapısı, olayları yorumlama biçimi, kendi kişiliklerine yaptıkları yorumlar, duyguları ve davranışları danışma oturumlarında çalışılmaktadır. Sosyal fobi ile başa çıkmada ise pek çok yöntem kullanılmaktadır. Bunlardan biri de bilişsel davranış̧̧ı müdahale yaklaşımlarıdır. Yaklaşımda, sorunun altında yatan uyum sağlayıcı olmayan inançları keşfetmek, bunların çeşitli yöntemler ile gerçekliğini, mantıksal olupolmadığını sorgulamak, işlevsiz davranışların yerine sağlıklı ve gerçekçi davranışlar oluşturmak amaçlanmaktadır. Psikolojik danışma oturumlarında danışanın sorununu belirlemek ve tanımlamak için psikolojik danışman ve danışan işbirliği içinde çalışır. Ortaya çıkan semptomlarını ortadan kaldırmak amaçlıdır; amaçlara ulaşabilmek için uygulanabilir planlar yapılır. Uygulanabilirlikten kasıt, danışana sorun ile başa çıkmasında beceri öğretilmesidir. Öğrenilen beceriler ev ödevi olarak verilir, danışan tarafından oturumlar arasında uygulanır. Bilişsel davranışçı psikolojik danışma ulaşılabilir ve uygulanabilir amaçları nedeniyle kısa sürelidir (Türkçapar, 2012).

Bilişsel davranışçı temelli müdahalelerle sosyal fobi çalışılırken, genel olarak ilk oturumlarda grubun yapılandırılması, kuralları belirlenmesi ve sosyal kaygı konusunda üyelerin bilgilendirilmesi yapılmaktadır. İlerleyen oturumlarda sosyal beceri geliştirme, problem çözme becerisi geliştirme, girişkenlik, bilişsel yapılandırma üzerinde durulmaktadır. Gerçek yaşam deneyimleri ise ödev olarak verilebilmektedir. Son oturumda ise danışmanın sonlandırılması tartışılmakta ve gelecek planları üzerinde durulmaktadır (Hayward ve diğerleri, 2000). Oturumlarda kaygı derecelendirme, zihinden geçen düşünceleri yakalama ve kaydetme (Rapee, Spence, Cobham ve Wignal, 2000), maruz bırakma (Kashdan ve Herbert, 2001), gevşeme eğitimi (Beidel ve Turner, 1998), düşünce hatalarını bulma ve düzeltme (Friedberg ve McClure, 2002) gibi teknikler kullanılabilmektedir. 
Bilişsel davranışçı yaklaşımın ergenlerin sosyal kaygıları üzerindeki etkililiğini belirlemek üzere Scaini, Belotti, Oglari ve Battaglia (2016) geniş bir meta-analiz çalışması gerçekleştirmişlerdir. Medline ve PsycInfo veri tabanından sosyal fobi üzerinde BDT temelli, çocuk ve ergenler üzerinde yapılan grup çalışmalarından 207 çalışmayı meta analize tabi tutmuşlardır. 2000-2014 yılları arasında Norveç, ABD, İspanya, Almanya ve Avusturalya'da yapılan araştırmalardır. Analiz sonuçlarına göre, toplam oturum sayısı ve terapinin hafta sayısı arttıkça bilişsel davranışçı yaklaşımın sosyal fobi üzerindeki etkisi artmaktadır. Tek bir oturum süresinin anlamlı bir etkisi bulunmamıştır. Bilişsel davranışçı yaklaşım, sosyal beceri eğitimi şeklinde sosyal fobi gruplarında uygulandığında etkililik artmaktadır. Ailenin terapiye katılmasının terapinin etkililiği üzerinde de bir etkisi olmadığ 1 gibi, yaş değişkenine göre de sonuçlarda farklılıklar oluşmamıştır. Tüm bu veriler, sosyal fobi gruplarında bilişsel davranışçı yaklaşımın çocuk ve ergen gruplarında etkili ve kullanılabilir olduğunu göstermektedir.

Sosyal fobi ile çalışırken, literatürde mizah da bir değişken olarak ele alınmıştır. Samson, Lackner, Weiss ve Papousek (2012) sosyal fobinin, mizah duygusunu zayıflattığını ifade etmektedir. Mizahı kullanamamak, sosyal fobili bireyin bir kaybı olarak görülmektedir. Mizah, eğlenme amacı ile geliştirilen, güldürme amacı taşıyan, insanlar tarafından eğlenceli algılanan, düşünce ve duygu süreçlerinden yararlanılan bir davranıştır. Dört farklı türü bulunmaktadır. Bunlardan ikisi olumlu, ikisi ise olumsuz mizah tarzları olarak görülmektedir. Olumlu ve uyumlu olanlar katılımcı ve kendini geliştirici mizah; olumsuz ve uyumsuz olan tarzlar ise saldırgan ve kendini yıkıcı mizahtır. Mizah, diğerlerine zarar vermeden, kullanan kişinin ilişkilerini zenginleştirme amacı taşıyorsa, katılımcı mizah olarak adlandırılır. Yine kişi eğlenme amacı taşıyarak, birine zarar verme amacı gütmeden mizahı kullanırsa adı kendini geliştirici mizah olmaktadır. Diğerlerine olumsuz etki edecek şekilde, vücut kusurları üzerinden dalga geçmek gibi, kendi kazancı acısından mizah kullanılırsa bu saldırgan mizahtır. Kendini yıkıcı mizah ise kendini olumsuz duruma düşürecek bir şekilde ve insanlarla ilişkileri geliştirme amacı taşıyarak yapılan mizahtır (Erickson ve Feildstein, 2007). Yapılan çalışmalarda (Tucker ve diğerleri, 2013), mizah tarzları ve sosyal kaygı arasındaki ilişkiyi inceledikleri çalışmalarında katılımcı ve kendini geliştirici mizahın, depresyon ve sosyal fobiyle negatif yönde, kendini yıkıcı mizahın da depresyon ve sosyal fobi ile pozitif yönde ilişkili olduğu bulunmuştur. Saldırgan mizahın ise sosyal fobi ile ilişkili olmadığı sonucuna ulaşılmıştır.

Mizahın ve türlerinin tanımlanmasından sonra, psikolojik danışma sürecine olan katıkılarını belirtmek gerekir. Psikolojik danışma ortamında bir durumun, bir yorumun mizahi içeriğinin çalışılması bilişsel yeniden işleme sürecini başlatır. Danışan, danışma ortamına getirdiği problemini, mizahın katkısı ile farklı biçimde yorumlayabilir. Farklı yorumlayan danışan, akıl yürtüme becerilerini kullanır. Problemin üstesinden gelirken, ek olarak akıl yürütme becerisi edinebilir (Canestrari, Branchini, Bianchi, Savardi ve Burro, 2018). Ayrıca mizahın psikolojik danışma ortamında danışan için anlamı, bir çeşit başa çıkma becerisi kazanması, duygularını ifade edebilmesi, yaşamıdaki memnuniyesizliği mizah ile ifade edebilmesi olabilmektedir. Mizah kullanımını öğrenen danışan ise yaşamda var olan direçlerini kırmaya başlar (Dionigi ve Canestrari, 2018a). Psikolojik danışmanlar için bakıldığında mizah, danışan ikilemde kaldığında veya durumun ironik yönlerini göstermede kullanılabilir. Mizahın bu şekilde kullanımı ile psikolojik danışman, danışanın kaygılarından ve üzüntülerinden kaynaklanan olumsuz duyguların hafiflemesini amaçlamaktadır. Kaygı, endişe gibi duyguların yerine daha olumlu duyguların hissedilmesi için çalışı1ır (Corey, 2005).

Beck'e (1976) göre mizah duygusu, fonksiyonel olmayan inançlara üzerinde büyük bir etki bırakır ve kişinin dikkatini mizahla fonksiyonel olmayan inancına yöneltmesini sağlar. Danışanların çarpık düşünceleri ile kendileri arasına mesafe koymasına, alternatif bilişler ve davranışlar oluşturmasına yardımcı olur. Beck, bilişsel yaklaşımda özellikle mizahın kullanılması ile bir şey yazmamış olmasına rağmen; en terapötik anların mizah kullanıldığı anlar olduğunu belirtmektedir. Akılcı duygusal terapide ise mizah, danışanların irrasyonel düşüncelerinin çalışılmasında, sık kullanılan ve güçlü bir tekniktir. Ellis, terapide danışanlarını irrasyonel düşüncelerini incelemeye cesaretlendirmiş ve düşüncelerinin içeriğinin gerçekten çok komik olduğunu buldurmaya gayret etmiştir (Ellis ve MacLaren, 1998). 
Tüm bu bilgiler ışığında, çalışmanın amacı, BDT temelli bir grupla psikolojik danışma programı geliştirerek, bu programın ergenlerin sosyal fobi ve mizah düzeylerine etkisini incelemektir. Denenceler ise:

1- Grupla psikolojik danışmaya uygulamasından önce deney ve kontrol gruplarının sosyal kayg1 ve mizah düzeyleri farklılaşmamaktadır.

2- Grupla psikolojik danışma uygulamasından sonra, sosyal kaygı ve mizah düzeyleri açısından deney grubu son test puanları ile kontrol grubu son test puanları deney grubu lehine farklılaşacaktır.

3- Grupla psikolojik danışma uygulamasından sonra deney grubu ön test-son test sosyal kaygı ve mizah puanları arasında son test puanları lehine farklılaşma olacaktır.

4- Grupla psikolojik danışma uygulamasından sonra kontrol grubu ön test-son test sosyal kaygı ve mizah puanları arasında farklılaşma olmayacaktır.

\section{Yöntem}

Bu çalışma, ön test-son test kontrol gruplu gerçek deneysel modelde hazırlanmış bir araştırmadır. Deneysel çalışmalar, neden sonuç ilişkisi üzerine kurulan, bir veya daha fazla bağımlı değişkenin, bağımsız değişken üzerindeki etkisinin ortaya çıkardığı değişimi incelemek amacıyla yapılan araştırmalardır. Deneysel araştırmalar, bilimsel yöntemler arasında en kesin sonuçların elde edildiği araştırma yöntemidir; çünkü araştırmacılar karşılaştırılabilir yöntemler uygulayabilir, etkilerini inceleyebilir (Büyüköztürk, Çakmak, Akgün, Karadeniz ve Demirler, 2010).

\section{Örneklem/çalışma grubu}

Çalışma, 2017 yılında, Kocaeli ilinde yer alan bir lise yapılmıştır. Deney ve kontrol gruplarını oluşturmak için 106 öğrenciye Sosyal Kaygı Ölçeği ve Mizah Ölçeği uygulanmıştır. Ölçekten alınan puanlara göre 26 öğrenci rastlantısal olarak seçilmiştir. 26 öğrenciden ön test puanlarının farklılaşmamasına dikkat edilerek, rastlantısal olarak 13 'er kişilik deney ve kontrol grupları oluşturulmuştur. Deney ve kontrol grubuna ait bilgiler Tablo l'de verilmiştir.

Tablo 1.

Deney ve Kontrol Grubunun Cinsiyetlere Dağılımı

\begin{tabular}{ccccccc}
\hline \multirow{2}{*}{ Grup } & \multicolumn{2}{c}{ Kiz } & \multicolumn{2}{c}{ Erkek } & \multicolumn{2}{c}{ Toplam } \\
\cline { 2 - 7 } & $\mathrm{N}$ & $\%$ & $\mathrm{~N}$ & $\%$ & $\mathrm{~N}$ & $\%$ \\
\hline Deney & 8 & 61.5 & 5 & 38.5 & 13 & 100 \\
Kontrol & 7 & 53.8 & 6 & 46.2 & 13 & 100 \\
\hline
\end{tabular}

Tablo 1'e göre deney grubu 8 kız $(\% 61,5) 5$ erkek $(38,5)$ toplam 13 kişiden oluşmaktadır. Kontrol grubunda ise $7 \mathrm{k} 1 \mathrm{z}(\% 53,8) 6$ erkek $(46,2)$ toplam 13 kişi vardır. Deney grubunda 4 tane 9. sinıf $(\% 30,8), 4$ tane 10 . sinıf $(\% 30,8), 5$ tane 11 . sinıf öğrencisi $(\% 38,4)$ bulunmaktadır. Yine kontrol grubunda 4 tane 9 . sinıf $(\% 30,8), 4$ tane 10. sinıf $(\% 30,8), 5$ tane 11 . sinıf öğrencisi $(\% 38,4)$ vardır. Deney grubunda yaş için ortlama ve standart sapma değerleri $15,16 \pm 1,35$; kontrol grubunda $15,29 \pm 1,46$ 'dir.

\section{Veri toplama araçları}

Sosyal Kaygı Ölçeği: Sosyal Kaygı Ölçeği Özbay ve Palancı (2001) tarafından tarafından geliştirilmiştir. Öğrencilerinin yaşadığı sosyal kaygı içerikli durumları değerlendirmek amaçlanmıştır. Üniversite öğrencilerinin sosyal durumlara uygun becerilerini ve bu durumlarda oluşabilecek kaygılarını ölçebilecek yapıda hazırlanmıştır. Kriter geçerliği için SCL-90 Ölçeği'nin ilgili beş alt ölçeği, Rathus Atılganlık Envanteri ve MMPI testinin Sosyal İçedönüklük alt testi kullanılmıştır. Yapı geçerliğine göre 30 maddelik üç faktörlü bir yapı ortaya çıkmıştır. Faktörler sosyal kaçınma, kritize edilme kaygısı ve bireysel değersizlik duygusu olarak 
adlandırılmıştır. Üç faktörün açıkladığı toplam varyans \% 32.9 'dur. MMPI sosyal içe dönüklük alt testi ile .43, SCL alt testlerinden kişiler arası ilişkilerde duyarlılık alt testi ile .51, kaygı testi ile .25 , fobik kaygı alt testi ile .36 , depresyon alt testi ile .40 , düzeyinde korelasyon bulunmuştur. Cronbah Alfa değeri .89'dur. Ölçek likert tipi 0-4 aralığında beşli derecelendirmeye sahiptir. Alınan puanların yükselmesi sosyal kaygı düzeyinin yükseldiği anlamına gelmektedir.

Ergenlikte Mizah Ölçeği: Ergenlikte Mizah Ölçeği Oral (2004) tarafından geliştirilmiş, 35 maddelik bir ölçektir. Dörtlü likert tipindedir. Üç alt boyutu bulunmaktadır. Faktör 1, mizahın öğrenme, dikkat, hatırlama gibi bilişsel işlemleri güçlendirmek için kullanılmasını içermektedir. Faktör 2, karşı cinsle ve bireylerarası iletişim ve etkileşimde mizahın kullanılmasını ölçmektedir. Faktör 3, korku ve kaygıyla başa çıkarken mizahın kullanılması amacıyla kulanılmaktadır. Cronbach Alpha iç tutarlılık değeri .89'dur. İç tutarlılık katsayısı Faktör 1 için .79, Faktör 2 için .77 ve Faktör 3 için .74 bulunmuştur.

\section{İşlem}

Hazırlanan ve uygulanan program, Marmara Üniversitesi Rehberlik ve Psikolojik Danışmanlık doktora programı Bilişsel-Davranışçı Kuram ve Uygulamaları dersinde, ders öğretim üyesi süpervizyonunda hazırlanmış ve uygulanmıştır. Oturumlara başlamadan önce hem katılımcılara hem ailelerine bilgi verilmiş, katılım konusunda onay alınmıştır. Oturumlar haftada bir kez düzenlemiş, süre olarak 90 dakika devam etmiştir. Oturumlar üç aylık süreye yayılmıştır. Kontrol grubu ile herhangi bir çalışma gerçekleştirilmemiştir. Ön test uygulamaları deney ve kontrol grubu için oturumlara başlanmadan; son test uygulamaları deney grubu için son oturumda, kontrol grubu için oturumlar bittikten sonra uygulanmıştır.

Oturumların içeriği genel itibari ile şöyle özetlenebilmektedir: İlk oturumda danışanların grupla psikolojik danışma hakkında bilgi sahibi olmalarını sağlamak, grubun tanışmasını ve ilişki kurulmasını sağlamak, grup kurallarını oluşturmak, sosyal fobi hakkında bilgi vermek ve paylaşımda bulunmak amaçlanmıştır. İkinci oturumda düşünce süreçleri hakkında bilgi sahibi olmaları ve farkındalık kazanmalarını sağlamak, düşünme biçimlerini ve içeriğini öğrenmelerini sağlamak, sosyal fobileri ile bağlantılı olduğu düşünme biçimleri arasındaki bağı kurmalarını sağlamak oturumun gündeminde bulunmuştur. Üçüncü oturumda duygu süreçleri hakkında bilgi sahibi olmaları ve farkındalık kazanmalarını sağlamak, pozitif, negatif, nötr duyguları ve içeriğini öğrenmelerini sağlamak, sosyal fobileri ile bağlantılı olduğu duyguları arasındaki bağı kurmalarını sağlamak bu oturumda çalışılan konulardır. Duygu kartları kullanılan materyaldir. Danışanların sosyal fobilerini başlatıcı olaylar hakkında farkındalık sahibi olmasını sağlamak, sosyal fobilerinin ortaya çıkmasında etkili olan düşüncelerinin farkına varmalarını sağlamak, olay ve düşünce ile birlikte verilen duygusal ve davranışsal tepkiler arasında bağ kurmalarını sağlamak, Bilişsel Davranışçı Yaklaşım hakkında bilgilenmelerini sağlamak dördüncü oturumun içeriğidir. $\mathrm{ABC}$ formu bu oturumda kullanılmıştır. İletişimin ne olduğunu, sürecini ve iletişim biçimlerini öğrenmelerini sağlama, iletişim biçimlerini kullanma beşinci oturumun içeriğidir. $\mathrm{Bu}$ oturumda iletişim kalıplarını daha iyi kullanabilmeleri ve için tabu oyunu oynamıştır. Altıncı oturumda bilişsel çarpıtmaları öğrenmelerini sağlamak, sosyal fobi ile kullandıkları bilişsel çarpıtmalarının ilişkisini kurmalarına yardımcı olmak bu oturumda amaçlardır. Bilişsel çarpıtmalar çalışma formu, bilişsel çarpıtmalar listesi kullanılmıştır. Yedinci oturumda bilişsel yaklaşımın D-E-F basamaklarını ele alınmıştır. Katılımcıların otomatik düşüncelerini, ara inançlarını ve temel inançlarını fark etmeleri ve bunları tartışmaları amaçlanmıştır. Böylece otomatik düşünce, ara inanç ve temel inançları ile bilişsel çarpıtmalar ve sosyal fobileri arasındaki bağlantıyı kurmalarını sağlamalarına yardımcı olunmuştur. Bu amaca yönelik olarak otomatik düşünceler, ara inançlar, temel inançlar çalışma kağıdı; otomatik düşünceler, ara inançlar, temel inançlar formu, DEF çalı̧̧ma kağıdı kullanılmıştır. Sekizinci oturumda danışanların mizahın ne olduğunu ve türlerini tanımasını sağlamak, videolar üzerinden mizah türünü eşleştirmelerini istemek, sosyal fobi ile mizah arasındaki ilişkiyi incelemek amaçlanmıştır. Mizah türlerini içeren çalışma kâğıdı ve videolar kullanılmıştır. Danışanların mizah duygularını geliştirebilecekleri yaratıcı düşünme ve analoji kullanmayı öğrenmelerini sağlama, mizahi öğeleri hayatlarına 
yansıtmalarını sağlama, mizahın kullanımı ile sosyal fobilerindeki değişimi inceleme dokuzuncu oturumda amaçlanmıştır. Mizah, yaratıcı düşünme ve benzetim konularını içeren çalışma kâğıdı kullanılmıştır. Son oturumda grupla psikolojik danışma oturumlarının özetlenmesi, bu deneyiminin sosyal fobileri ve mizah duyguları üzerindeki etkilerinin tartışılması, son testlerin uygulanması ve vedalaşma ile çalışmanın sonlandırılması gerçekleşmiştir.

\section{Verilerin analizi}

Ölçeklerle veri toplanmadan önce, kullanabilmek için gerekli izinler alınmıştır. Ölçek uygulanırken katılımcılara neden ölçekleri dolduracakları hakkında bilgi verilmiştir. Öğrencilere katılımcılar arasında seçim yapılacağı ölçeklerin üzerine isim ve soy isimlerini yazmaları söylenmiştir. Ayrıca ölçekleri gönüllük esasına göre doldurmuşlardır. Betimleyici veriler için frekans, yüzde, ortalama ve standart sapmalar kullanılmıştır. Verilerin normal dağılıma uyup uymadığını test etmek için Shapiro-Wilk-W testi yapılmış, çarpıklık ve basıklık değerlerine bakılmıştır. Verilerin normal dağılım göstermediği görülmüştür. Bu nedenle deney ve kontrol gruplarının sosyal kaygı ve mizah ölçeği puanlarının farklılaşıp farklılaşmadığını saptamak için non-parametrik Mann-Whitney U ve Wilcoxon testi kullanılmıştır. Analizler SPSS 20 programı ile yapılmıştır.

\section{Bulgular}

Çalışmanın bu bölümünde deney ve kontrol grubuna ait ortalama ve standart sapma tablosu, deney ve kontrol gruplarının ön test-son test sosyal kaygı ve mizah puan ortalamalarının karşılaştırılmasını gösteren Mann-Whitney U Testi tabloları verilmiştir. Tablo 2'de deney ve kontrol gruplarına ait ortalama ve standart sapmalar gösterilmiştir.

Tablo 2.

Deney ve Kontrol Grubu Için Ortalama ve Standart Saplamalar

\begin{tabular}{clcccc}
\hline \multirow{2}{*}{ Grup } & & \multicolumn{2}{c}{ Sosyal Fobi } & \multicolumn{2}{c}{ Mizah } \\
\cline { 3 - 6 } & & $\overline{\mathrm{X}}$ & $\mathrm{Ss}$ & $\mathrm{X}$ & Ss \\
\hline \multirow{2}{*}{ Deney } & Ön Test & 74.46 & 10.91 & 79.31 & 15.92 \\
& Son Test & 43.15 & 18.62 & 90.08 & 14.73 \\
& Ön Test & 75.38 & 12.43 & 74.62 & 15.77 \\
& Son Test & 68.46 & 18.14 & 71.53 & 15.26 \\
\hline
\end{tabular}

Tablo 2'ye bakıldığında deney grubu ön test için sosyal fobi ölçeği puan ortalamalarının 74,76 , standart sapmasının 10,91; son test için puan ortalaması 43,15 ve standart sapmasının 18,82 olduğu görülmektedir. Yine deney grubu mizah ölçeğinden alınan puan ortalamaları ve standart sapmaları sırasıyla ön test için 79,31 ve 15,92 'dir. Son test puan ortalamaları ve standart saplamaları 90,08 ve 14,74 'tür. Kontrol grubunun sosyal fobi ölçeği ön test puan ortalamaları 75,38 , standart sapmalar1 12,43 'tür. Son test puan ortalamalar1 68,46 , standart sapmalar1 18,14 'tür. Kontrol grubunun mizah ölçeği ön test puan ortalamaları 74,62, standart sapmaları 15,77'dir. Son test puan ortalamaları 71,53 ve standart sapmaları 15,26 'dır.

Tablo 3'te sosyal kaygı ölçeği ve mizah ölçeği ortalama puanları, deney ve kontrol grubunun ön testleri açısından Mann-Whitney U Testi ile karşılaştırılmıştır.

Tablo 3.

Deney ve Kontrol Gruplarının Ön Test Puanlarının Karşılaştırılması

\begin{tabular}{ccccccc}
\hline Değişken & Grup & $\mathrm{n}$ & Sıra Ort. & Sıra Top. & $\mathrm{U}$ & $\mathrm{p}$ \\
\hline Sosyal Kayg1 & Deney & 13 & 13.27 & 172.5 & 81.5 & .878
\end{tabular}


Bilişsel Davranışçı Yaklaşım Temelli Bir Psikolojik Danışma Programının Ergenlerin Sosyal Fobi ve Mizah Düzeylerine Etkisi

\begin{tabular}{ccccccc}
\multirow{4}{*}{ Mizah } & Kontrol & 13 & 13.73 & 178.5 & & \\
& Deney & 13 & 14.73 & 191.5 & \multirow{2}{*}{68.5} & .414 \\
\hline
\end{tabular}

Tablo 3 incelendiğinde, sosyal fobi ölçeği puan ortalamalarının, deney ve kontrol grubu ön test ve son test puanları açısından farklılaşmadığ $\breve{g}_{1}$ örülmektedir $(U=81,50, p>.05)$. Benzer şekilde deney ve kontrol grubu ön test ve son test mizah ölçeği puanlarında da farklılaşma görülmemektedir ( $U=68,50, p>.05)$. "Grupla psikolojik danışmaya uygulamasından önce deney ve kontrol gruplarının sosyal kaygı ve mizah düzeyleri farklılaşmamaktadır" hipotezi doğrulanmıştır.

Tablo 4'te sosyal kayg1 ölçeği ve mizah ölçeği ortalama puanları, deney ve kontrol grubunun son testleri açısından Mann-Whitney U Testi ile karşılaştırılmıştır.

Tablo 4.

Deney ve Kontrol Gruplarının Son Test Puanlarının Karşılaştırılması

\begin{tabular}{ccccccc}
\hline Değişken & Grup & $\mathrm{n}$ & Sıra Ort. & Sira Top. & $\mathrm{U}$ & $\mathrm{p}$ \\
\hline \multirow{2}{*}{ Sosyal Kayg1 } & Deney & 13 & 9.35 & 121.5 & \multirow{2}{*}{30.5} & $.00^{*}$ \\
& Kontrol & 13 & 17.65 & 129.5 & & \\
\multirow{2}{*}{ Mizah } & Deney & 13 & 17.46 & 227.0 & \multirow{2}{*}{33.0} & $.00^{*}$ \\
& Kontrol & 13 & 9.54 & 124.0 & & \\
\hline
\end{tabular}

$* \mathrm{p}<.05$

Tablo 4 incelendiğinde, sosyal kaygı ölçeği ölçeğinden elde edilen puanlar, deney ve kontrol gruplarında, deney grubu lehine farklılaşmaktadır $(U=30,50, p<.05)$. Buna göre grupla psikolojik danışma uygulamasından sonra sosyal kaygı ölçeği puanları, deney grubu lehine istatistiksel olarak anlamlı şekilde azalmıştır. Ayrıca mizah puan ortalamaları, ön test-son test açısından deney grubu lehine farklılaşmaktadır $(\mathrm{U}=33,00, \mathrm{p}<.05)$. Bu sonuca göre grupla psikolojik danışma uygulamasından sonra mizah ölçeği puanları, deney grubu lehine anlamlı yükselme göstermiştir. Bu sonuca göre "Grupla psikolojik danışma uygulamasından sonra, sosyal kaygı ve mizah düzeyleri açısından deney grubu son test puanları ile kontrol grubu son test puanları deney grubu lehine farklılaşacaktır" hipotezinin doğrulandığı görülmektedir.

Tablo 5 'te mizah ve sosyal kaygı deney grubu ön test-son test puanlarının Wilcoxon Testi ile karşılaştırılması verilmiştir.

Tablo 5 .

Mizah ve Sosyal Kaygı Deney Grubu Ön Test-Son Test Puanlarının Karşıllaştırılması

\begin{tabular}{ccccccc}
\hline Değişken & Sıralar & $\mathrm{n}$ & Sira Ort. & Sira Top. & $\mathrm{z}$ & $\mathrm{p}$ \\
\hline Sosyal & Negatif Sıralar & 11 & 7.45 & 82.00 & & \\
Kayg1 & Pozitif Sıralar & 2 & 4.50 & 9.00 & -2.55 & $.01^{*}$ \\
Ön Test-Son & Eşit & 0 & & & & \\
Test & Toplam & 13 & & & & \\
& Negatif Sıralar & 0 & 0.00 & 0.00 & & \\
Mizah & Pozitif Siralar & 11 & 6.00 & 66.00 & -2.95 & $.00 *$ \\
Ön Test-Son & Eşit & 2 & & & & \\
Test & Toplam & 13 & & & & \\
*p<.05 & & & & &
\end{tabular}

Tablo incelendiğinde deney grubunun sosyal kaygı ön test son test puanları arasında anlamlı olarak farklılaşma görülmektedir. Grupla psikolojik danışma sonrasında deney grubunun sosyal kaygı son test puanları, ön test puanlarından anlamlı olarak düşüktür $(Z=-2,55, p<.05)$. Ayrıca, deney grubunun mizah puanları, ön test ve son test açısından anlamlı olarak 
farklılaşmaktadır. Grupla psikolojik danışma sonrasında deney grubunun mizah son test puanları, ön test puanlarından anlamlı olarak yüksektir $(Z=-2,95, \mathrm{p}<.05)$. "Grupla psikolojik danışma uygulamasından sonra deney grubu ön test-son test sosyal kaygı ve mizah puanları arasında son test puanları lehine farklılaşma olacaktır" hipotezinin doğrulandığı görülmektedir.

Tablo 6'da mizah ve sosyal kaygı kontrol grubu ön test-son test puanlarının Wilcoxon Testi ile karşılaştırılması gösterilmiştir.

Tablo 6.

Mizah ve Sosyal Kaygı Kontrol Grubu Ön Test-Son Test Puanlarının Karş1laştırılması

\begin{tabular}{ccccccc}
\hline Değişken & Siralar & $\mathrm{n}$ & Sira Ort. & Sira Top. & $\mathrm{z}$ & $\mathrm{p}$ \\
\hline Sosyal & Negatif Sıralar & 5 & 4.90 & 24.50 & & \\
Kayg1 & Pozitif Sıralar & 6 & 6.92 & 41.50 & -.764 & .45 \\
Ön Test-Son & Eşit & 2 & & & & \\
Test & Toplam & 13 & & & & \\
& Negatif Sıralar & 4 & 8.79 & 4.88 & & \\
Mizah & Pozitif Siralar & 6 & 13.41 & 5.92 & \multirow{2}{*}{.818} & .41 \\
& Eşit & 3 & & & & \\
Ön Test-Son & Toplam & 13 & & & & \\
Test & & & & & & \\
\hline
\end{tabular}

Tablo 6'ya bakıldığında sosyal kaygı için kontrol grubu ön test ve son test puanları istatistiksel olarak farklılaşmamaktadır $(Z=-, 764, p>.05)$. Benzer şekilde mizah için kontrol grubu ön test ve son test puanları arasında anlamlı farklılaşma bulunmamaktadır ( $\mathrm{Z}=-, 818, \mathrm{p}>.05)$. "Grupla psikolojik danışma uygulamasından sonra kontrol grubu ön test-son test sosyal kaygı ve mizah puanları arasında farklılaşma olmayacaktır" hipotezi doğrulanmıştır.

\section{Tartışma, Sonuç ve Öneriler}

$\mathrm{Bu}$ araştırma, bilişsel davranışçı yaklaşımı sosyal fobi ve mizah üzerindeki etkililiğini test etmek amacı ile grupla psikolojik danışma programı geliştirme ve geliştirilen programın etkililiğini sınamak amacıyla gerçekleştirilmiştir. On oturum olarak gerçekleştirilen uygulamanın etkiliğinin sinanmasina yönelik analizlerden elde edilen bulgulara göre, deney grubu ve kontrol grubu ön test sosyal fobi ve mizah ölçeği puanları arasında farklılaşma yoktur. Grupla psikolojik danışma oturumları bittikten sonra, deney grubunun sosyal fobi puanları kontrol grubuna göre daha düşük çıkarken, mizah ölçeği son test puanları ise anlamlı olarak yüksek bulunmuştur. Kontrol grubunda ise ön test ve son test sosyal fobi ve mizah ölçeği puan ortalamaları açısından herhangi bir fark olmadiğı bulunmuştur.

Bilişsel davranışçı yaklaşım yetişkin, ergen ve çocukların sosyal fobilerinin sağaltılmasında kullanılan psikolojik danışma yaklaşımlarından biridir. Ergenlerle yapılan bir çalışmada, bilişsel davranışçı yaklaşımın kısa ve uzun dönemli etkilerine bakılmıştır. Bilişsel davranışçı yaklaşımın, kısa dönemde ve terapiyi izleyen bir yıl içinde semptomları azalttığı ortaya koyulmuştur. $\mathrm{Bu}$ etkililik ergenin yaşı ve depresyona sahip olup olmamasına göre değişmemektedir. Yani ergen depresyona sahip olsa bile bilişsel davranışçı yaklaşımın sosyal fobi üzerindeki etkinliği devam etmektedir. Buna ek olarak, sosyal beceri içermeyen bilişsel davranışçı yaklaşımın sosyal fobi üzerindeki etkinliği ortalama 7,4 yılken; sosyal beceri kazandırmayı da hedefleyen bilişsel davranışçı yaklaşımın etkisi daha uzundur. Ergenler terapi ortamında kazandıkları becerileri yetişkinliklerine de taşıyabilmektedir (Kerns, Read, Klugman ve Kendall, 2013). Yaş aralığı 12-16 olan ergenler ile iki yıl süren bir diğer çalışmada (Hullu, Sportel, Nauta ve Jong, 2017) bilişsel davranışçı yaklaşımın, sınav kaygısı ve sosyal fobide anlamlı düşmeye sonuç verdiği ortaya çıkmıştır. İki yıl sonra alınan ölçümlerde ise son test ölçümleri ile farklılaşma olmadığı belirtilmektedir. Bunun yanı sıra, iki yıl sonraki ölçümlerde, bilişsel davranışçı yaklaşımın benlik saygısı, pro-sosyal davranışlar ve negatif değerlendirilme korkusu üzerindeki etkiliği devam etmektedir. Öte yandan O'Toole, Watson, Rosenberg ve 
Berntsen'in (2018) yetişkin grup ile, sosyal kaygı üzerinde BDT temelli grupla psikolojik danışma çalıştıkları araştırmalarında, deney grubunun sosyal kaygı düzeyi anlamlı olarak düşmüştür. Ayrıca, üç ay sonra yapılan izleme çalışmasında da bilişsel davranışçı yaklaşımın uzun süreli etkisinin olduğu görülmüştür. Cuijpers, Gentili, Bonos, Garcia-Compayo, Botella ve Cristea (2016) Pubmed, PsycInfo, Embase, Cochrane veri tabanlarından aldıkları panik bozukluk, sosyal fobi ve yaygın anksiyete bozukluklarında BDT uygulamalarının gerçekleştirildiği makaleler ile meta-analiz çalışması yapmışlardır. Elde edilen sonuçlara göre, BDT uygulamaları sosyal fobi ve yaygın anksiyete bozukluğu üzerinde anlamlı bir farklılık oluşturmamıştır. BDT uygulamaları, sosyal fobinin semptomların giderilmesinde ve danışanların beceri geliştirmesinde anlamlı olarak etkili bulunmuştur. Bir başka çalışmada (Spence, Donovan, March, Kenardy ve Hearn, 2017). Sosyal fobi sorunu olanlara çevrimiçi BDT oturumları uygulanmıştır. Avrupa, Afrika, Asya, Avusturalya, Yeni Zelanda, İngiltere, Kanada, Amerika'dan katılımcıların yer aldığ çalışma çocuklar (8-12 yaş) ve ergenler (13-17 yaş) olmak üzere iki ayrı grupta yürütülmüştür. 12 haftalık uygulama sonrasında hem çocuk hem ergen grubunun sosyal fobi seviyesinde anlamlı düşme gözlemlenmiştir. Ayrıca ailelerden alınan değerlendirme ölçekleri son testlerine göre de sosyal fobide anlamlı düşme mevcut olmakla birlikte, 6 ay sonra alınan izleme ölçümlerinde bir farklılaşma olmadığı; yani terapinin etkisinin devam ettiği bulunmuştur. Mcaleavey, Catonguay ve Goldfried (2014) çalışmalarında, sosyal fobide bilişsel davranışçı yaklaşımını uygulayan 276 terapistten sosyal fobi için kullandıkları tekniklerin yanı sıra danışanların tedaviyi güçleştiren koşulları, davranışları ve düşünceleri ile ilgili bilgi almışlardır. Bulgular, terapistlerin \%99.6'sının sosyal fobide, bilişsel davranışçı temelli psiko-eğitimi kullandıklarını göstermiştir. Sosyal fobinin şiddeti, süresi-kronikliği ve zayıf sosyal beceriler, danışanın tedaviyi güçleştiren durumlarılorak belirlenmiştir. Tedaviyi güçleştiren danışan davranışlarını ise direktiflere direnç gösterme, ev ödevlerini yapmama, bağımsız çalışma becerisinin olamaması, kaçınmacı kişiliğe sahip olmaları şeklinde sıralamışlardır. Danışanların tedaviyi güçleştiren, en sık karşılaşılan üç düşünceleri ise terapistin her şeyi yapacağı beklentisi, terapi süreci için pesimist tavır-tedavinin olumlu sonuçlanmayacağına inanma, sosyalleşmenin fobilerini yok etmeyeceklerine inanmaları olmuştur.

Çalışmamızda ulaşılan sonuçlar ile literatür bilgileri arasında uyum olduğu görülmektedir. Bilişsel davranışçı yaklaşımın yapılandırılmış oturumlarının yanında oturum içeriklerinin çeşitlendirilmesi yapılan müdahalenin etkili olmasında rol oynamıştır. Oturum içeriklerine yakınsayan, ıraksayan, eleştirel, yaratıcı düşünme biçimleri eklenmiş, danışanlar sosyal fobilerini bu düşünme biçimleri ile açıklamışlardır. Duygu tanıma çalışmaları ile danışanların farkındalıkları arttırılmıştır. İletişim becerisi geliştirme çalışmalarına oturum olarak yerilmiştir. Mizahın karikatürler ve videolar üzerinden somuta dökülerek çalışılmasının da psikolojik danışma oturumlarının sosyal kaygı ve mizah üzerinde etkili olmasına yol açtığı düşünülmektedir.

Bilişsel davranışçı yaklaşım, mizahı çeşitli biçimlerde kullanmaktadır. Terapide mizahın kullanılması bilişsel yeniden yapılandırmayı kolaylaştırmaktadır ve danışanın kendini kabulünü arttırmaktadır. Bilişsel davranışçı yaklaşım bu noktada, olumsuz deneyimlerde bile mizahi öğe bulmaya çalışarak, danışanların negatif duygulanımlarını azaltmaya çalışmaktadır (Lefcourt, ve diğerleri, 1995). Sistematik duyarsızlaştırma ve kaygının basamaklandırılması aşamasında, danışana korktukları durumları daha iyi derecelendirmeleri açısından mizahla yardım edilebilmektedir. Mizahın kullanıldığı derecelendirme, geleneksel kaygı derecelendirmesinden daha etkili olabilmektedir (Ventis, Higbee ve Murdock, 2001). Ginsberg (2014) 64 katılımc1 ile mizah duygusunun sosyal fobi üzerindeki etkisini, bilişsel davranışçı yaklaşıma dayalı psikoeğitim ile çalışmıştır. 17-22 yaş aralığındaki üniversite öğrencilerinden oluşan çalışmada deney grubuna sadece mizahi içeriği olmayan sosyal kaygı videoları; diğer gruba ise sosyal kaygı ile ilgili mizahi videoları izletilmiştir. Araştırma sonuçlarına göre her iki psiko-eğitim çalışması da sosyal fobi düzeyinde düşmeye yol açmıştır. İki grubun son testleri arasında farklılaşma yoktur. Yani, bu araştırmanın sonucuna göre mizahın sosyal fobide kullanılması etkilidir; fakat sadece sosyal fobi eğitimi verilen gruba göre üstünlügü yoktur. Dionigi ve Canestrari (2018b) kaygi bozukluklarına ve yeme bozukluğuna sahip 8 danışan ile yapılan BDT oturumlarının içeriğini 
konuşma analizi ile incelemişlerdir. Danışanların biri yeme bozukluğuna, diğerleri kaygı bozukluklarına sahiptir. Mizahın BDT oturumlarında işlevi çalışma sonucunda ortaya çıkarılmıştır. Mizahın üç işlevi ise danışman ile anlaşmanın bir yolu olması, danışman ile aynı fikirde olduğunu ifade etmesi ve danışman ile farklı düşündügünü ifade etmesidir. Mizah danışmanlardan daha çok danışanlar tarafından kullanılmaktadır. Danışanlar kaygılarını ortadan kaldırmak için mizahı kullanmaktadırlar. Danışmanlar ise, danışan mizah kullandığında, anlatmaya devam etmesi için onu teşvik etmekte ve mizahı olumlu bulmaktadırlar.

Bilişsel davranışçı temelli grupla psikolojik danışma uygulamasının gerçekleştirildiği çalışmamızda, mizah son test puanları deney ve kontrol gruplarında, deney grubu lehine farklılaşırken; deney grubu son test puanları da ön test puanlarına göre anlamlı derecede yüksek çıkmıştır. Bu sonuç uygulanan programın mizah üzerinde etkili olduğunu göstermektedir.

Scaini, Belotti, Oglari ve Battaglia'ya (2016) göre BDT oturumlarının sayısı arttıkça, BDT'nin sosyal fobi üzerindeki etkisi artmaktadır. Ayrıca, sosyal beceri eğitiminin, sosyal fobi gruplarında uygulandığında etkililiğin arttığını da vurgulamışlardır. Çalışmamızda oturum sayısının 10 hafta olmasının, bu oturumların yaklaşık 3 aylık sürece yayılmasının ve psikolojik danışmada iletişim ve mizahın beceri olarak kazandırılmaya çalışılmasının, anlamlı farkın çıkmasına yol açtığı düşünülmektedir.

Literatüre bakıldığında sosyal fobi ve mizahın birlikte çalışıldığı araştırmalar çok kısıtlıdır. Sosyal fobi ve mizahın, bilişsel davranış̧̧ı yaklaşım temelli çalışıldığı bir adet (Ginsberg, 2014) psiko-eğitim çalışması bulunmuş, mizah ve sosyal fobinin bir arada bilişsel davranışçı yaklaşım ile çalışıldığ $\mathrm{Bu}$ nedenle bu araştırmanın mizah ile birlikte sosyal kaygı çalışan psikolog ve psikolojik danışmanlara yarar sağlayacağı düşünülmektedir. Ayrıca uygulanan oturumlar, okul rehberlik servislerinde ve kliniklerde uygulanabilir şekilde hazırlanmıştır. Öte yandan izleme çalışmasının yapılmaması araştırmanın kısıtlılı̆̆ıdır. Diğer araştırmacılara izleme çalışmasının da yapılacağı deneysel çalışmalar önerilebilir. Mizah oturumları sadece iki oturum şeklinde uygulanmıştır. $\mathrm{Bu}$ sınırlılığı ortadan kaldırmak için, gelecek araştırmacılar mizah ile ilgili oturum sayısını arttırabilir. Ayrıca ergen grubunda uygulanan oturumların, daha sonraki çalışmalarda diğer yaş dönemlerinde de uygulaması yapılabilir. Böylece yaş değişkeninin etkisi ve sosyal fobinin karşılaştırmalı şekilde ele alınması mümkün olabilmektedir. Ayrıca sosyal kaygı ve mizah değiş̧kenlerinin yanına iletişim becerileri, öz yeterlik gibi değişkenler eklenerek regresyon ve yol modeli çalışmaları planlanabilir. Araştrmamız deneysel bir çalışma olmasına rağmen plecebo grubu kurulmamıştır. Bu durumçalışmanın bir sınırlılığıdır. Sonraki araştırmacılara plecebo grubu oluşturmaları önerilebilir. Okul rehberlik servislerinde görevli psikolojik danışmanlar sosyal fobi çalışırken mizah ögelerini danışma oturumlarına ekleyebilirler. Ayrıca psikolojik danışmanlar sosyal fobiye sahip danışanların iletişim kurmakta ve sürdürmekte olan zorluklarını göz önüne alabilirler. Bu nedenle standart BDT oturumlarına geçmeden iletişim zorluklarının çalışıldığı oturumları danışma sürecine ekleyebilirler.

\section{Kaynaklar}

American Psychiatric Association. (2013). Diagnostic and statistical manual of mental disorders (5th ed.). Washington, DC.

Beck, A. T. (1976). Cognitive therapy ad the emotional disorders. New York: Meridian.

Beidel, D. C. ve Turner, S. M. (1998). Shy children, phobic adults: The nature and treatment of social phobia. Washington DC: American Psychological Association.

Büyüköztürk, Ş., Çakmak, E. K., Akgün, Ö. E., Karedeniz, Ş. ve Demirel, F. (2010). Bilimsel araştırma yöntemleri. Ankara: Pegem Akademi.

Burstein, M., He, J. P., Kattan, G., Albano, A. M., Avenevoli, S. ve Merikangans, K. R. (2011). Social phobia and subtypes in the national comorbidity survey-adolescent supplement: Prevalence, correlates, and comorbidity. Journal of the American Academy of Child \& Adolescent Psychiatry, 50, 870-880.

Canestrari, C., Branchini, E., Bianchi, I., Savardi, U. ve Burro, R. (2018). Pleasures of the mind: What makes jokes and insight problems enjoyable. Frontiers in Psychology, 8, 1-21. 
Corey, G. (2005). Gestalt theory. L. Gebo ve S. Gesicki (Yay. haz.). Theory and practice of counseling and psychotherapy içinde (ss. 192-223). Belmont, CA: Brooks/Cole.

Cuijpers, P., Gentili, C., Banos, R. M., Garcia-Campayo, J., Botella, C. ve Cristea, I. A. (2016). Relative effects of cognitive and behavioral therapies on generalized anxiety disorder, social anxiety disorder and panic disorder: A meta-analysis. Journal of Anxiety Disorders, 43, 79-89.

Dilbaz, N. (1997). Sosyal fobi. Psikiyatri Dünyast, 1, 18-24.

Dionigi, A. ve Canestrari, C. (2018a). The use of humor by therapists and clients in cognitive therapy. The European Journal of Humour Research, 6(3), 50-67.

Dionigi, A. ve Canestrari, C. (2018b). The role of laughter in cognitive-behavioral therapy: Case studies. Discourse Studies, 20(3), 323-339.

Ellis, A. ve MacLaren, C. (1998). Rational emotive behavior therapy: A therapist's guide. Atascadero, CA: Impact Publishers.

Erickson, S. J. ve Feldstein, S. W. (2007). Adolescent humorandits relationship to coping, defense strategies, psychological distress and well-being. Child Psychiatry and HumanDevelopment, 37, 255-271.

Friedberg, R. D. ve McClure, J. M. (2002). Clinical practice of cognitive therapy with children and adolescents: The nuts and bolts. New York: The Gilford Press.

Ginsberg, R. E. (2014). Effects of problem relevant humor on anxiety, symptomacceptance, and behavioral engagement in socially anxious young adults (Yayımlanmamıs doktora tezi). Hofstra University, New York.

Hayward, C., Varady, S., Albano, A. M., Thienemann, M., Henderson, L. ve Schatzberg, A. F. (2000). Cognitive-behavioral group therapy for social phobia in female adolescents:

Results of a pilot study. Journal of the American Academy of Child and Adolescent Psychiatry, 39(6), 721-726.

Hullu, E., Sportel, B. E., Nauta, M. H. ve Jong, P. J. (2017). Cognitive bias modification and CBT as early interventions for adolescent social and test anxiety: Two-year follow-up of a randomized controlled trial. Journal of Behavior Therapy and Experimental Psychiatry, $55,81-89$.

Kashdan, T. B. ve Herbert, J. D. (2001). Social anxiety disorder in childhood and adolescence: Current status and future directions. Clinical Child and Family Psychology Review, 1, 37-60.

Kerns, C. M., Read, K. L., Klugman, J. ve Kendall, P. C. (2013). Cognitive behavioral therapy for youth with social anxiety: Differential short and long-term treatment outcomes. Journal of anxiety disorders, 27(2), 210-215.

Lefcourt, H. M., Davidson, K., Shepherd, R., Phillips, M., Prkachin, K. ve Mills, D. (1995). Perspective-taking humor: Accounting for stress moderatio. Journal of Social \&Clinical Psychology, 14(4), 373-391.

McAleavey, A. A., Castonguay, L. G. ve Goldfried, M. R. (2014). Clinical experiences in conducting cognitive-behavioral therapy for social phobia. Behavior Therapy, 45(1), 2135.

Mcnail, D. W. ve Randall, C. R. (2014). Conceptualizing and describing social anxiety and its disorders. S. G. Hofmann ve P. M. DiBartolo (Yay. haz.). Social anxiety: Clinical, developmental, and social perspectives içinde (ss. 3-26). Elsevier.

Oral, G. (2004). Ergenlikte mizah ölçeği. Eğitim ve Bilim, 29(133), 20-27.

O'Toole, M. S., Watson, L., Rosenberg, N. K. ve Berntsen, D. (2018). Changes in perceived centrality of anxious events following cognitive behavioral therapy for social anxiety disorder and panic disorder. Journal of Behavior Therapy and Experimental Psychiatry, 59, 150-156.

Özbay, Y. ve Palancı, M. (2001). Sosyal Anksiyete Ölçeği: Geçerlik ve güvenirlik çalışması. VI. Ulusal Psikolojik Danışma ve Rehberlik Kongresi'nde Sunulmuş Bildiri, (5-7Eylül), Orta Doğu Teknik Üniversitesi, Ankara. 
Samson, A. C., Lackner, H. K., Weiss, E. M. ve Papousek, I. (2012). Perception of other people's mental states affects humor in social anxiety. Journal of Behavior Therapy and Experimental Psychiatry, 43(1), 625-631.

Scaini, S., Belotti, R., Ogliari, A. ve Battaglia, M. (2016). A comprehensive meta-analysis of cognitive-behavioral interventions for social anxiety disorder in children and adolescents. Journal of Anxiety Disorders, 42, 105-112.

Spence, S. H., Donovan, C. L., March, S., Kenardy, J. ve Hearn, C. (2017). Generic versus disorder specific cognitive behavior therapy for social anxiety disorder in youth: A randomized controlled trial using internet delivery. Behaviour Research and Therapy, 90, 41-57.

Stein, D. J. ve Hollander, E. (2002.) Textbook of anxiety disorders. Washington DC: American Psychiatric Publishing.

Tucker, R. P., Judah, M. R., O'Keefe, V. M., Mills, A. C., Lechner, W. V. ve Davidson, C. L. (2013). Humor styles impact the relationship between symptoms of social anxiety and depression. Personality and Individual Differences, 55(7), 823-827.

Tükel, R. (2009). Anksiyete bozuklukları. I.B. Kulaksızoğlu, R. Tükel, A. Üçok, İ. Yargıç, O. Yazıcı (Yay. haz.). Psikiyatri, içinde (ss. 58-90). İstanbul: İstanbul Üniversitesi Basım ve Yayınevi.

Türkçapar, H. (2012). Bilişsel terapi: Temel ilkeler ve uygulama. Ankara: HYB Yayınları.

Ventis, W. L., Higbee, G. ve Murdock, S. A. (2001). Using humor in systematic desensitization to reduce fear. The Journal of General Psychology, 128(2), 241-253.

\section{Extended Abstract \\ Introduction}

Social phobia is defined as "continuous fear when the person will be evaluated by others; be afraid to be humiliated by other people, be embarrassed by this situation or fall into a ridiculous position in the eyes of other people". People who have social phobia experience fear of being evaluated negatively and fear of falling in the social environment, when they need to perform. This fear causes people with social phobia to be extremely aware of themselves and tend to criticize themselves. With these emotions, the body provides physiological responses such as flushing, palpitations, sweating and shaking (Dilbaz, 1997). The American Psychiatric Association (2013) evaluated social phobia as a disorder in DSM-V and suggested some criteria for diagnosis. Criterias are fear or anxiety in the social situation in which someone can be evaluated; the person's fears of behaving in a way that is self-negative or to show symptoms of anxiety; always creating fear or anxiety in these social situations, avoiding these social situations, and facing with great fear or anxiety if they cannot avoid; feeling the fear and anxiety extremely high according to social criterias; these emotions or avoidances are continuous and have existed for six months or more.

According to cognitive approaches, people with social phobia evaluate social events as threatening and develop irregular beliefs related to themselves or their behavior in the context of social events. Irregular beliefs can be seen like "I shouldn't let them understand that I'm worried", "If my thought is wrong, i would fall into a bad situation", "I am an untalented, boring, unloved person" (Stein \& Hollender, 2002). Irregular beliefs of people who have social phobia are not caused by other people's evaluations. The negative beliefs of those people with social phobia are based on the impressions they give to others about how they appear (Tükel, 2009).

While working with social phobia, humor is also considered as a variable in the literature. Samson, Lackner, Weiss and Papousek (2012) say that social phobia weakens the sense of humor. The inability to use humor is seen as a damage of social phobia. Humor is a behavior developed for fun, laughing. Humor is perceived as fun by people; thought and emotion processes of humor are used in psychological counseling sessions. There are four different types for humor. Two of them are seen as positive, and two are seen as negative humor styles. Positive and harmonious ones are affiliative and self-enhancing humor styles. Negative and incompatible styles are aggressive and self-destructive humor. If humor aims to enrich the person's relationship, this style 
is called affiliative humor. If the person uses humor aiming to fun, without aiming to cause harm others, the humor becomes self-enhancing humor. It is the aggressive humor, if humor is used in terms of him/her own gain, which adversely affect others, such as making fun of body flaws. Selfdestructive humor style is the using of humor in a way that negates herself/himself (Erickson \& Feildstein, 2007). The aim of this study are to develop a CBT-based group counseling program and to investigate the effect of this program on social phobia and humor levels of adolescents. The hypothesis are:

1. Social anxiety and humor levels of experimental and control groups do not differ before the application of psychological counseling program.

2. After psychological counseling program, the results of the posttest scores of the experimental group and control group in terms of social anxiety and humor levels will be different in favor of the experimental group.

3. After psychological counseling program, there will be differentiation in favor of posttest scores between pre-test-post-test social anxiety and humor scores of experimental group.

4. After psychological counseling program, there will be no difference between the pre-testpost-test social anxiety and humor scores of the control group.

\section{Method}

This study was designed in the experimental model with pretest-posttest control group. Experimental studies are the researches conducted to investigate the change in the effect of one or more dependent variables on the independent variable, which are based on cause and effect relationship. Experimental research is the most accurate method among scientific methods; because, researchers can apply comparable methods, examine their effects (Büyüköztürk, Çakmak, Akgün, Karadeniz \& Demirler, 2010).

Social Anxiety Scale and Humor Scale were applied to 106 students in order to form experiment and control groups. Experimental and control groups were formed randomly from 26 students by taking into consideration that pre-test scores were not differentiated. The participant number of experimental and control groups is 13 . There were 8 girls (61.5\%) and 5 boys (38.5\%) in the experimental group. In the control group, there were 7 girls (53.8\%) and 6 boys (42.8\%). Data were collected with the Social Anxiety Scale (Özbay \& Palanc1, 2001) and the Humor Scale in Adolescence (Oral, 2004).

The prepared and applied program was prepared and applied in the lecture program of Marmara University, Psychological Counseling and Guidance Program in Cognitive-Behavioral Theory and Applications course, under supervision of lecturer. Both the participants and their families were informed before the application of program. Sessions held once a week and continued for 90 minutes. The sessions were held for three months. 10 sessions have been made. No study was made with the control group. Pre-test applications were taken before the start of the sessions for the experimental and control groups. Post-test applications were taken in the last session for the experimental group. Post-test was applied after the end of the sessions for the control group.

Frequency, percentage and standard deviations were used for descriptive statistics. MannWhitney $\mathrm{U}$ and Wilcoxon test were used to determine whether the scores of the social anxiety and humor scale differed for the experimental and control groups. The analyzes were performed with SPSS 20 program.

\section{Result and Discussion}

In order to test the effectiveness of the cognitive behavioral approach on social phobia and humor, we aimed to develop a psychological counseling program and test the effectiveness of the program. According to the findings from the analysis, there is no difference between the experimental group and the control group in terms of pre-test scores of social phobia and humor scales. After group counseling sessions were finished, social phobia scores of the experimental group were lower than the control group; also the post-test scores of the humor scale were 
significantly higher. In the control group, there was no difference in the mean scores of pre-test and post-test social phobia and humor scale.

In studies which Cognitive Behavioral Therapy has been worked in social phobia on children and adolescents, it is stated that CBT causes a significant decrease in social phobia level (Cuijpers et al., 2016; Hullu, Sportel, Nauta \& Jong, 2017; Kerns, Read, Klugman \& Kendall, 2013; Mcaleavey, Catonguay \& Goldfried, 2014; O'Toole, Watson, Rosenberg \& Berntsen, 2018). The number of publications in which humor has been worked via Cognitive Behavioral Therapy is low. In one study, it was reported that cognitive behavioral therapy had a positive effect on humor (Ginsberg, 2014).

The sessions were prepared as applicable in school guidance services and clinics. There is no follow-up study; so this is a limitation for this research. Experimental researches with follow-up CBT based social phobia studies are recommended for other researchers. In addition, the sessions applied in the adolescent group can also be applied for children and adults in other studies. Thus, it is possible to approach the social phobia in a comparative manner and to see the effect of age variable. Due to the intangible structure of humor, sessions should be organized in a concrete way for children. In addition, social anxiety and humor can be studied with communication skills and self-efficacy in a path model. 